Bou Hatoum, M., El Mustapha, R., Nassar, C, Zaheraldeen, H., and Hamzeh, F. (2018). "Lean Methods to Improve End User Satisfaction in Higher Education Buildings." In: Proc. $26^{\text {th }}$ Annual Conference of the International. Group for Lean Construction (IGLC), González, V.A. (ed.), Chennai, India, pp. 187-198. DOI: doi.org/10.24928/2018/0250. Available at: www.iglc.net

\title{
LEAN METHODS TO IMPROVE END USER SATISFACTION IN HIGHER EDUCATION BUILDINGS
}

\author{
Makram Bou Hatoum ${ }^{1}$, Reina El Mustapha ${ }^{2}$, Christelle Nassar ${ }^{3}$, \\ Hayyan Zaheraldeen ${ }^{4}$ and Farook Hamzeh ${ }^{5}$
}

\begin{abstract}
End user satisfaction is one of the major indices that attest to the success of a project in terms of adding value to the client. Therefore, in order to rate the overall functions of a facility, the fulfilment of end users' needs is to be taken into consideration during the whole project phase (i.e. design through operation). Many clients believe that allocating more resources to the project automatically guarantees the success of the project. What they fail to realize is that in most cases, success, which should be translated in end user satisfaction, relies more on how the project was thought of, planned, constructed and delivered. This paper presents the case study of a high-budget engineering complex. In this study, different end users of the facility were prompted to fill a comprehensive survey about the overall quality of the complex. Interviews were also conducted with the client representative and other parties who were involved during the design/construction phases. After results were analysed and compared, an evident contradiction was detected: end user satisfaction rates were relatively low whereas client's representative overall satisfaction was optimistically high. Lean methods and tools were suggested that could be used to improve the design and delivery of similar facilities and establish a higher end user satisfaction rate.
\end{abstract}

\section{KEY WORDS}

Post-Occupancy Evaluation, End User Satisfaction, Higher Education, Lean Construction, Building Performance.

\section{INTRODUCTION}

Studies show that seven of the top ten industries with the highest growing rates in the USA for 2017 are construction related (Sageworks2017), and the pace of expansion in the global construction industry is expected to continue growing through 2021 with an average of 2.8\% (Construction Intelligence Center2017). But how to measure success in

1 Graduate Student, Civil and Environmental Engineering Department, American University of Beirut, Beirut, Lebanon,mnb23@mail.aub.edu

2 Graduate Student, Civil and Environmental Engineering Department. American University of Beirut, Beirut, Lebanon, rse33@mail.aub.edu

3 Graduate Student, Civil and Environmental Engineering Department, American University of Beirut, Beirut, Lebanon, cjn07@mail.aub.edu 
Makram Bou Hatoum, Reina El Mustapha, Christelle Nassar, Hayyan Zaheraldeen and Farook Hamzeh

the construction industry? And is value to the end user a factor frequently considered? In fact, success has been previously closely tied to only three main parameters: cost, time \& quality. Other criteria has been added such as safety, functionality and satisfaction including user expectation and satisfaction (Chan and Chan 2004).However, many construction companies rarely implement new knowledge from recent research to assess different parameters related to the user's perspective in their work. Such companies ignore the fact that input from end-users is important as to learn from previous projects to continuously improve and apply this new knowledge to design future projects (Vischer 2009). One way to improve current practices is to implement Post-Occupancy Evaluations (POE) in order to assess the operation requirements of existing buildings; generate new knowledge about the human use of space and give feedback on key decisions made during the design and construction phase. Since the 1960's universities have been a main part of the POE exercise, given the fact that each university has its own design and construction standards and that there is no general design standard for higher education as a whole (Tookaloo and Smith 2015). Value for end users in higher education, is a building that creates optimal conditions for teaching, learning, and research (Spiten, Haddadi, Støre-Valen, \& Lohne, 2016).

As per Hay et al. (2017), POE is considered a highly reliable index that allows researchers to learn from previous projects and improve in upcoming ones. Improvements need to be based on the needs, desires and satisfaction of the occupants. To achieve that and deliver projects with higher value to the users, Lean methods that improve value generation and eliminate waste can be applied. These methods can ensure value throughout the lifetime of buildings and should be considered more often and more seriously (Spiten, Haddadi, Støre-Valen \& Lohne, 2016).

However, POEs have a few short comings. It might show a focus on short-term thinking to achieve direct financial profits rather than long-term benefits to clients and society. Other issues include liability and accountability issues where participants in a project fear that POE will only focus on the negative aspects, holding different parties (architect, contractor, structural engineer, etc.) accountable and responsible for defects. Finally, another important issue is the lack of policies and legislations that demand the use of POE regularly. Eventually, applying POE enables a wider perspective and encourages owners to investigate the needs of the users, and offer satisfying building design quality in return.

Conducting research in different types of buildings (educational, residential, healthcare, etc.) enables a deep insight about the needs of the end users (Watson et al 2014). When talking about user's satisfaction, Ornstein and Ono (2010) define various ways of obtaining information including interviews with key persons and POEs through questionnaires with scales of values to measure users' satisfaction levels regarding the respective environments.

4 Graduate Students, Civil and Environmental Engineering Department, American University of Beirut, Beirut, Lebanon, hnz04@mail.aub.edu

5 Assistant Professor, Civil and Environmental Engineering Department, American University of Beirut, Lebanon, +9611350000ext 3616, fax +961 1744462, fh35@aub.edu.lb 
Feedback is the information provided by an external agent regarding a process performance measure ( $\mathrm{Li}$ et al 2012). The feedback model presented by Sombra et al. (2011), suggested that clients unsatisfied needs identified from satisfaction surveys should be transformed into new design parameters through the feedback model. They concluded that this feedback process can help create value for users and allows innovation to achieve continuous improvement. A contrasting but complementary view to feedback is feed forward, translated in end-user involvement in the pre-design phase and focused on good communication, understanding end-user value, and innovation to achieve adaptability in the building to cope with rapid changes in academia (Spiten, Haddadi, Støre-Valen, \& Lohne 2016). These Lean behaviors (feedback and feed forward) help in realizing maximum value on a project.

Very few existing reviews provide a direct comparison and examples of facilities that satisfy their owners and dissatisfy their end users, especially when it comes to educational facilities. This paper provides a direct example of a high-budget educational complex that satisfies its owners and dissatisfies its end users. With this example, the paper attempts in improving future design and construction decisions in education facilities and reinforcing the importance of implementing some lean tools and shifting from traditional to more developed thinking for higher end user satisfaction.

\section{METHODOLOGY}

The building considered in this research is the Irany Oxy Engineering Complex (IOEC), one of American University of Beirut's newest engineering facilities.IOEC is made of 6 floors and 2 basements that provide the faculty of engineering with more than 60 highly equipped teaching and research laboratories, six state-of-the-art classrooms including an e-classroom and data center, and 85 cubicles for doctoral students. It is also the first building to register for LEED-NC certification, the gold standard of 'green design' in Lebanon (AUB, 2014).

The complex was subjected to a post occupancy evaluation exercise to measure the end-users satisfaction and evaluate whether implementing Lean approaches during the early lifecycle of design and construction could have enhanced it.

To carry out the study, an end-user satisfaction survey was designed and tested. The survey was distributed to different end users who use IOEC; that includes engineering students of different majors, staff working inside IOEC and professors. After gathering and analyzing the data, interviews were set with the operation manager of IOEC, a major end user of the complex, and AUB's Facility Design and Planning Unit (FPDU) representing the owner of the complex during design and construction. FPDU members were also asked to fill out the survey to compare their satisfaction level with the project to that of the end user. At the end, the importance and relevance of the results were evaluated, and suggest Lean solutions were suggested that may help improve the end user satisfaction for future projects.

The survey was divided into two major parts. The first part deals with personal information related to the end user such as gender and occupation, time spent inside the complex and his or her overall quality satisfaction with IOEC's classroom, offices, laboratories, lounges and cafeteria. The second part of the survey included eight main 
sections to calculate the satisfaction index. The first section was related to the complex's accessibility and whether the end users are satisfied with the horizontal and vertical circulation. The second section targeted the complex's design and furniture and whether the latter allows for comfortable learning, removes distractions and permits varied communication and comfortable mobility; this section also targeted washrooms. The third, fourth, fifth and sixth sections dealt with the air quality inside the complex, thermal comfort (temperature convenience and control), visual comfort (satisfactory lighting conditions)and acoustical comfort (noise level inside the classrooms) respectively. The seventh section targeted the overall cleanliness and the last section expressed whether the end users feel secure and safe inside the complex.

The minimum number of survey participants needed was calculated using Sloven's formula (Kanire, 2013):

$n=\frac{N}{1+N e^{2}}$

Where $\mathrm{N}$ is the total number of population benefiting from IOEC which is around 3800 (AUB, 2016) and e is the margin of error (assumed 0.01 for a $90 \%$ confidence level). Thus, the sample size $\mathrm{n}$ shall be 98 participants. They were asked to indicate the extent of their satisfaction with different building performance aspects by rating them on a scale from 1 to 5 . After obtaining the results, the satisfaction index was calculated using the following formula (Dominowski, 1980):

Satisfaction Index $(S I)=\frac{\sum_{i=1}^{5}\left(a_{i} \llbracket \mathbb{\square}\right)\left(x \rrbracket_{i}\right)}{5 \sum_{i=1}^{5} x_{i}} * 100 \%$

The response for $\mathrm{i}$ is 1, 2, 3, 4, 5 and is illustrated as follows:

- $\mathrm{x}_{0}=$ frequency of "Strongly Agree" response with $\mathrm{a}_{0}=5$

- $\mathrm{x}_{1}=$ frequency of "Agree" response with $\mathrm{a}_{1}=4$

- $\mathrm{x}_{2}=$ frequency of "Neutral" response with $\mathrm{a}_{2}=3$

- $\mathrm{x}_{3}=$ frequency of "Disagree" response witha $3=2$

- $\mathrm{x}_{4}=$ frequency of "Strongly Disagree" response witha $4=1$

The scale adopted to establish the level of satisfaction is as follows (Hassanain, Mathar, \& Aker, 2016):

- A satisfaction index value above $80 \%$ suggests that the respondents are "Strongly Satisfied"

- A satisfaction index between $70 \%$ and $80 \%$ suggests that the respondents are "Mildly Satisfied"

- A satisfaction index between $50 \%$ and $70 \%$ suggests that the respondents are "Dissatisfied"

- A satisfaction index is below 50\% suggests that the respondents are "Strongly Dissatisfied" 


\section{RESULTS \& DISCUSSIONS}

A total of 104 end-users participated in this survey: AUB's engineering students majoring in different engineering programs formed around $93 \%$ of the participants $(55 \%$ undergraduate, $37 \%$ graduate and $1 \% \mathrm{PhD}$ ), while the remaining $7 \%$ varied between Professors (4\%) and staff (3\%). Overall, the respondents spend an average of 4.6 hours inside the complex. The survey was also filled by FPDU members that represent the client. After processing the obtained data from the distributed questionnaires, the overall quality satisfaction for IOEC's different facilities and the satisfaction index for the multiple performance criteria by both the client and the end users were obtained and discussed below.

\section{OVERALL QUALITY SATISFACTION WITH THE IOEC FACILITIES}

End-users were clearly dissatisfied with most of the facilities including offices $(68.67 \%$ SI), lecture rooms $(64.45 \%$ SI), cafeteria $(64.49 \%$ SI) and most notably lounges (57.35\%), barely showing mild satisfaction at the level of the labs (70\% SI). On the other hand, the client's representative had a totally opposite view. Results show a 100\% SI with labs and $90 \%$ SI with offices, lecture rooms and lounges indicating strong satisfaction. The client's representative was also considerably satisfied with the cafeteria $(80 \% \mathrm{SI})$. These significant differences clearly show that the facilities are not serving the needs of the end-users. The root cause of this significant difference would go back to the designs stages of IOEC were the client's representative should have better engaged the end-users and considered their entire needs in the preliminary stages; this in turn reflected in the end-users dominant dissatisfaction.

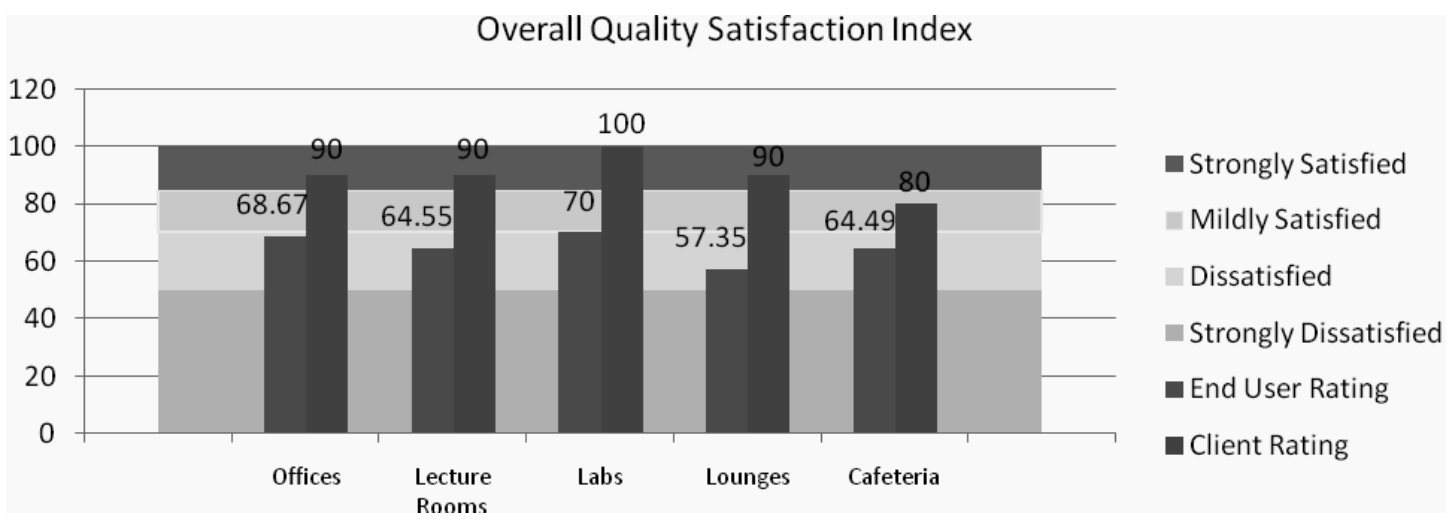

Figure 1: Overall Quality Satisfaction Index for IOXY's Major Facilities as rated by the End-Users and Client

\section{END-USER FEEDBACK}

Results of the survey as displayed in Figure 2 below show that users of the engineering complex, mostly students and faculty members, are generally satisfied with the accessibility to the complex (72\% SI) and felt secure and safe inside the building (72\% SI). Visual comfort also ranked high among the building users (71\% SI). 


\section{Overall Quality Satisfaction Index}

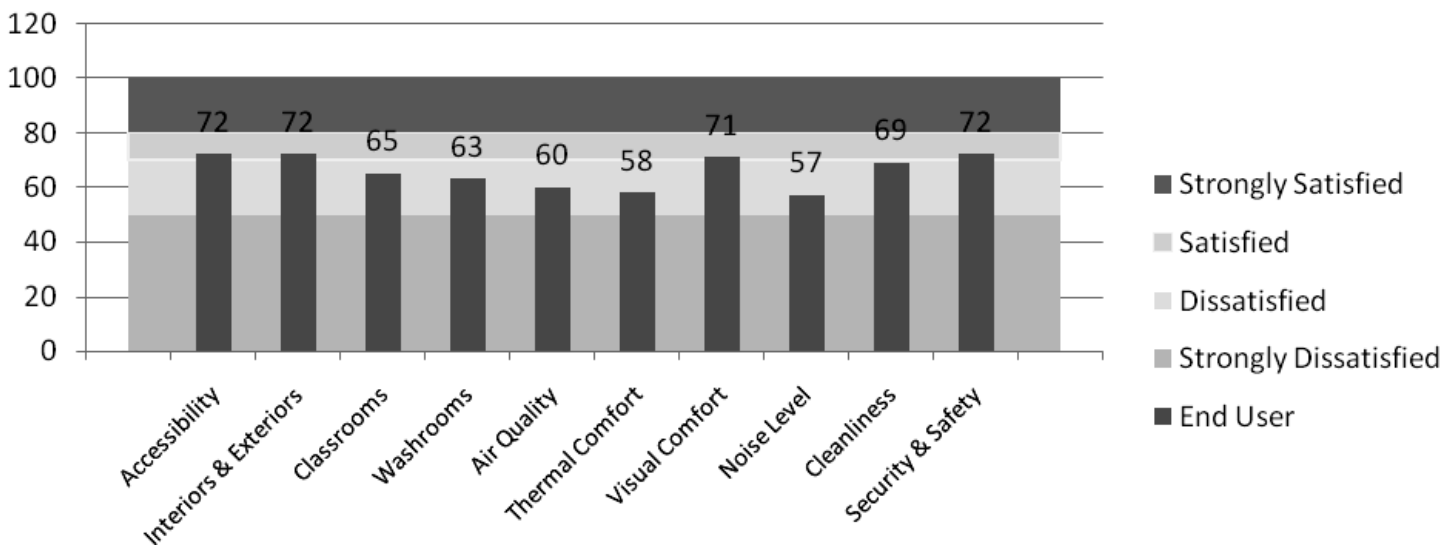

Figure 2: Satisfaction Index for IOXY's Performance Criteria as rated by the End-User

As for the Design \& Furniture section, users were mildly satisfied with the exterior design $(75 \%$ SI) and the corridor spacing (76\% SI). However, users were dissatisfied with the interior design of the building (69\% SI) and the quality and colors of the interior walls, floors and ceilings (67\% SI). According to the participants, classrooms offer an easy in/out access (79\% SI), but the design and furniture of these classrooms fail to provide a comfortable learning environment since it doesn't allow proper communication between professors and students (67\% communication SI) and doesn't provide comfortable mobility (63\% mobility SI). Student grouping is not facilitated (59\% SI) and outside distractions such as light and noise are present (58\% distraction SI). As for the washrooms, the users were satisfied with the easy access (70\% SI) but dissatisfied with the services $63 \%$ SI indicating uneasy use) and the area and number of the washrooms that fail to accommodate large numbers at peak times (53\% SI).

Furthermore, users were dissatisfied with the air quality inside the building (60\% SI), thermal comfort (58\% SI) and noise level (57\% SI). The building cleanliness was on the border of satisfying (69\% SI). According to the participants, the major reason for the dissatisfaction with the air quality and thermal comfort is the unavailable user access to air ventilation and temperature. As for the noise level, they believe the background noise level from mechanical and electrical systems inside the classrooms can get too high and thus affect the learning process.

\section{CLIENT'S REPRESENTATIVE FEEDBACK}

In contrast to the end-users' feedback, the client's representative showed a highly optimistic point of view. Results from Figure 3 below show strong satisfaction with the accessibility (93\% SI), visual comfort (95\% SI), air quality ( $87 \%$ SI), and the security and safety $(100 \%$ SI) sections. The client was also satisfied with the noise level, cleanliness (both $80 \% \mathrm{SI}$ ) and the thermal comfort (73\% SI). As for the design and furniture section, the client was strongly satisfied with the overall interior and exterior design (98\% SI) and 
washroom services and ease of use (93\% SI). However, the satisfaction index of the client slipped to $77 \%$ satisfaction index SI when it comes to classrooms because of some furniture changes after opening the complex.

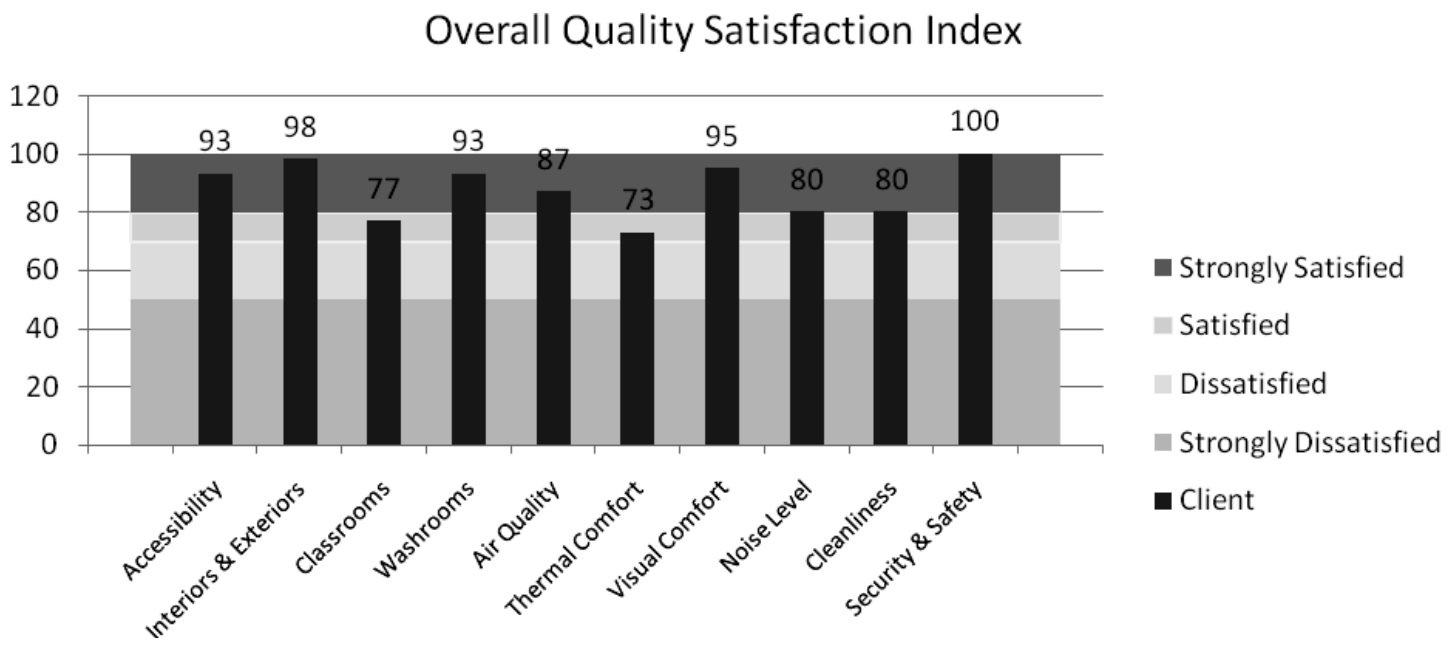

Figure 3: Satisfaction Index for IOXY's Performance Criteria as rated by the Client

\section{FURTHER DISCUSSIONS AND THE EFFECTS OF IMPLEMENTING LEAN TOOLS AND BEHAVIOURS}

Because of the obvious incompatibility between perspectives of the end users' and the client's representative and for further analysis, interviews were conducted with a senior project manager from American University of Beirut's FPDU (the Facility Planning and Design Unit representing the client), and the operation manager of the IOEC building (representing the end-user). The two interviews generated descriptive insights that the authors described and discussed using "what if lean was used" scenarios. Only sections that dissatisfy the end-user as seen in the table below are thoroughly and further discussed, leaving aside sections that satisfy the end-users such as accessibility, visual comfort and the security and safety inside the complex. However, it is important to mention that implementing lean tools and behaviors that will be discussed in this section may increase the SI of the satisfied sections even more.

Table 1: Satisfaction Index and Rate of Satisfaction (ROS) for the Major Survey Sections

\begin{tabular}{ccccc}
\hline & \multicolumn{2}{c}{ As Rated by End Users } & \multicolumn{2}{c}{ As Rated by the Client } \\
\hline Section & SI (\%) & ROS* & SI (\%) & ROS* \\
Accessibility & $72 \%$ & $\mathrm{~S}$ & $93 \%$ & $\mathrm{SS}$ \\
Design \& Furniture & $66 \%$ & $\mathrm{D}$ & $87 \%$ & $\mathrm{SS}$ \\
Interiors \& Exteriors & $72 \%$ & $\mathrm{~S}$ & $98 \%$ & $\mathrm{SS}$ \\
Classrooms & $65 \%$ & $\mathrm{D}$ & $77 \%$ & $\mathrm{~S}$ \\
Washrooms & $63 \%$ & $\mathrm{D}$ & $93 \%$ & $\mathrm{SS}$
\end{tabular}


Makram Bou Hatoum, Reina El Mustapha, Christelle Nassar,

Hayyan Zaheraldeen and Farook Hamzeh

\begin{tabular}{ccccc} 
Air Quality & $60 \%$ & D & $87 \%$ & SS \\
Thermal Comfort & $58 \%$ & D & $73 \%$ & S \\
Visual Comfort & $71 \%$ & S & $95 \%$ & SS \\
Noise Level & $57 \%$ & D & $80 \%$ & S \\
Cleanliness & $69 \%$ & D & $80 \%$ & S \\
Security \& Safety & $72 \%$ & S & $100 \%$ & SS \\
\hline
\end{tabular}

*ROS: SS (Strongly Satisfied), S(Satisfied), D(dissatisfied) and SD(Strongly Dissatisfied)

To begin with, the design of the building took about two years. Such durations are unusual for the design of such a building. Hence, one would have to assume that difficulties emerged during the design. Common obstacles often include hindered communication between the different entities working during the design phase. The construction phase was also delayed three years after finishing the design. Both delays not only increased the direct cost of design, estimated at around $\$ 700,000$, but also incurred other unnecessary costs due to the fluctuation of the prices of raw materials during this construction phase. Aside from that, there was no proper communication between the different parties involved in the design. The client's representative asked the different engineering faculties to forward them their needs and passed them to the design team without collaborative meetings between all three parties. Based on the insights above, the delays could have been avoided by using an integrated design approach: the client, designer and end users. Each engineering major would be represented by at least one faculty member who would carry the faculty and students' needs of the major that he or she represent. These representatives would collaborate during the design phase by conducting several meetings with both the designer and owner to discuss design details without having to use tedious requests for information (or RFIs). This approach would take into consideration inputs from end users who would be represented in the meetings. It would also enable the different entities to exchange information more easily, enhance communication, create a smooth working environment and ensure a common understanding of the whole design. In return, the final project would satisfy the end-users especially that their needs would be fulfilled. This approach can also be best achieved when it is coupled with Building Information Modeling (BIM) (Al Hattab and Hamzeh, 2013).It was also mentioned by the interviewees that the absence of false ceilings in the building was intended for educational purposes. However, the displayed mechanical equipment are causing noise problems and affecting students in class. Had an integrated design approach been used, different engineers would have been able to work in a way to prevent the acoustic and quality problems from happening. It should be added that during one of the interviews, the owner representative refused any suggested lean idea considering it as a "waste of time". Despite the obvious problems and delays, the owner's representative believes that miscommunication was never an issue during the design/planning/construction of the facility and the need for common meetings between themselves, design team and the end-users representatives was unnecessary.

Both the construction and design phases spanned longer than intended. During this period, new departments were introduced at AUB and needed to be accounted for. The chemical engineering program for example needed special lab equipment and machinery and allocated space. These changes in design impacted the cost. Other changes such as 
area expansion from $10,000 \mathrm{~m}^{2}$ to $15,000 \mathrm{~m}^{2}$ also contributed in cost increases. The construction cost of the buildings surpassed $\$ 24,000,000$, in comparison to the intended cost which was less than $\$ 10,000,000$. As mentioned before, using lean methods improve value generation and eliminate waste in both design and construction phases. Hence, the changes discussed above could have been easily prevented with the use of lean methods such as Target Costing. Target Costing is a way to account for a project cost without jeopardizing profit - or in the case of IOEC - while inducing cost savings and avoiding budget deviations. A suggested solution that could have helped in reducing the construction and design delays, predicting upcoming challenges and eliminating wastes would be implementing the Last Planner System (LPS) (Hamzeh et al. 2016). Implementing the system would have maintained better control of both budget and time while taking into account the changes that were happening in the engineering faculty. In addition to that, most of the design effort was deployed in the exterior design. In turn, mechanical, electrical and structural problems were generated and continue to be under maintenance. This is a major fallacy that happens often in the AEC industry. Local optimization jeopardizes quality and can disrupt the essential function of the building, in some cases. Therefore, the focus on globally optimizing the whole product and equally dividing the resources is the most suitable way to ensure quality, safety, aesthetics and functionality. For example, despite the fact that all floor tiling has the same print, it can be noticed while walking down the corridors or classrooms that the intensity of colors slightly differs. Aside from the low quality of the tiling, the general contractor did not abide by the provided installation plans from the tiling sub-contractor during installation. The above setbacks could have been tackled using Target Value Design (TVD) and Value Engineering. These measures contribute in maximizing value and sticking to a set budget. Another example of waste in the design and construction that would have been avoided by TVD was during the design of the exterior facades that control the intensity of sunlight and moderate the building's internal temperature. Some facades were designed and installed towards the North side; these facades are currently considered useless because the sunlight has no impact on this cardinal direction.

When it comes to classroom furnishing, modern classroom furniture that are both mobile and customized for student grouping was set up. However, traditionally minded stake holders objected to the modern furniture and asked for complete traditional classroom designs because some classes are to be used for exams. In return, all new furniture was removed and replaced by traditional designs, adding even more waste to the project. Innovative ideas would have been possible if stakeholders were involved and consulted early on in the design phase. The involvement of different stakeholders in the design phase not only guarantees enhanced communication and better understanding but also ensures quality, cost and time efficiencies. Collaboration of various parties and the alignment of interests of the shareholders is the basis of lean construction.

The insights gathered from the interviews, as seen above, explain the end-users' dissatisfaction with many IOEC services such as classroom furnishing, noise levels, thermal comfort and air quality and clearly show how the planning and construction processes of the complex affect the final product and the overall satisfaction rate. 


\section{CONCLUSIONS \&RECOMMENDATIONS}

The case study above for IOEC serves as a solid example to further proof the importance of involving end-users in the design of future projects, especially that the value of any construction project is always seen from the eyes of the customer. Big budgets and long planning processes do not necessarily guarantee end-user satisfaction if the end-users are not involved and value in the eyes of the end user is not explored.

The end user dissatisfaction in the engineering complex can be attributed to different reasons, some of which can be considered as subjective and the others mostlyrelated to the handling of the planning, design and construction phases. During the design and construction of the project, many issues between the different entities (contractor, AE, etc.) became apparent. These conflicts have contributed in one way or the other to the reduction in end user satisfaction.

In order to narrow down such conflicts in future projects, and fulfill a better end user satisfaction rate, a shift in planning perspective is needed and a number of lean management processes are to be implemented. Design and planning units in educational facilities such as the FPDU in AUB are encouraged to find lean innovative measures to improve design without impacting an increase in cost (e.g., Target Value Design, Target Costing, and LPS) and eliminate non-value adding activities and design concepts in order to reduce time and cost and increase overall value of the facility. They are also encouraged to command proper sharing of information and data (less tedious RFIs, enhanced communications) between the different stakeholders in order to help achieve value, explore different alternatives to come up with the most suitable in order to avoid rework or maintenance problems and apply global instead of local optimization. Most importantly, the design and planning team should align the client's needs with that of the end user and involve the latter as heavily as possible during the entire project phases to guarantee project satisfaction. Applying all the above is the first step towards Lean Project Delivery to increase the delivered value to the end user in terms of safety, quality and value fulfillment.

\section{FURTHER STUDY}

More studies can be performed to investigate the implementation of lean principles and methods that were suggested in this paper in future educational facilities construction projects. Further studied can even focus on convincing clients to shift from traditional to lean perspective to provide better quality projects and higher value to the end- user in the future.

\section{ACKNOWLEDGEMENTS}

The authors would like to thank all the students, faculty and staff members who participated in the survey. They would also like to thank Mr. Khaled Joujou, the operation manager of IOEC, and Ms. Magda Karam, a senior project manager in AUB's Facility Planning and Design Unit. 


\section{REFERENCES}

Al Hattab, M., Hamzeh, F.R. (2013) "Information Flow Comparison Between Traditional and BIM-Based Projects in the Design Phase", Proceedings for the 21st Annual Conference of the International Group for Lean Construction,Fortaleza, Brazil, pp 761-770.

AUB. (2014, September 9). AUB inaugurates forward-looking, eco-friendly, and research-oriented Irani-Oxy Engineering Complex. Retrieved from American Univeristy of Beirut: http://website.aub.edu.lb/news/2014/Pages/ioec.aspx

Blyth, A., Gilby, A., \& Barlex, M. J. (2006). Guide to Post Occupancy Evaluation. University of Westminster. England: HEFCE.

Chan, A. P., \& Chan, A. P. (2004). Key Performance Indicators for Measuring Construction Success. Benchmarking: An International Journal, 203-221.

Construction Intelligence Center (CIC). (2017). Global Construction Outlook 2021. Timetric.

Dominowski, R. (1980). Research methods. Englewood Cliff, NJ: Prentice-Hall.

Fabi, V., Andersen, R. K., \& Corgnati, S. (2016). Accounting for the Uncertainty Related to Building. Buildings.

Green, S. D., \& May, S. C. (2006). Lean Construction: Arenas of enactment, models of diffusion and the meaning of "leanness". Building Research and Information, 498511.

Hamzeh, F., Kallassy, J., Lahoud, M., and Azar, R. (2016). "The First Extensive Implementation of Lean and LPS in Lebanon: Results and Reflections." In: Proc. 24th Ann. Conf. of the Int'1. Group for Lean Construction, Boston, MA, USA, sect.6 pp. $33-42$

Hassanain, M. A., Aker, A., \& Mathar, H. (2016). Post-occupancy evaluation of a university student. Architectural Engineering and Design Management, 12(1), 67-77.

Kanire, G. (2013). Social science research methodology: Concepts, methods and computer applications. Germany: GRIN Verlag.

Karna, S., Junnonen , J.-M., \& Sorvala, V.-M. (2009). Modelling Structure of Customer Satisfaction with Construction. Journal of Facilities Management, 7(2), 111-127.

Kunkel, S., Kontonasiou, E., Arcipowsk, A., Mariottini, F., \& Atanasiu, B. (2015). Indoor Air Quality, Thermal Comfort and daylight . Buildings Performance Institute Europe (BPIE).

Li, W., Jin, L., Fischer, M., \& Kunz, J. (2012). Method using Metric Based Performance Feedback to Predict Client Satisfaction-A Hospital Case Study. Construction Research Congress.

Ornstein, S. W., \& Ono, R. (2010). Post-Occupancy Evaluation and Design Quality in Brazil: Concepts, Approaches and an Example of Application. Architectural Engineering and Design Management, 48-67.

Othman, A. A. (2015). An International Index for Customer Satisfaction in the Construction Industry. International Journal of Construction Management, 15(1), 3358.

Sageworks. (2017). The 10 fastest-growing industries in the U.S. Raleigh, N.C.: Sageworks. 
Sanni-Anibire, M. O., \& Hassanain, M. A. (2016). Quality Assessment of Student Housing Facilities. Architectural Engineering and Design Management, 12(5), 367380.

Sombra, P. L., Romcy, N. M., Sampaio, J. C., \& Neto, J. d. (2011). Application of a Model of Design Process Feedback From Measurement of Customer Satisfaction. 19th Annual Conference of the International Group for Lean Construction. Lima, Peru.

Spiten, T. K., Haddadi, A., Støre-Valen, M., \& Lohne, J. (2016). "Enhancing Value for End Users-A Case Study of End-User Involvement. Boston: IGLC.

Tookaloo, A., \& Smith, R. (2015). Post Occupancy Evaluation in Higher Education. Procedia Engineering, 515-521.

Vischer, J. C. (2011). Applying Knowledge on Building Performance: From Evidence to Intelligence. Intelligent Buildings International. 